\title{
A utilização do Word e Excel por alunos da EJA para criar subsunçores para uso de software Modellus
}

\author{
Daniel de Jesus Melo Santos \\ Sergio Luiz Bragatto Boss
}

\section{Resumo}

Este artigo apresenta os resultados de pesquisa desenvolvida junto a uma turma do Ensino Médio, na modalidade Ensino de Jovens e Adultos - EJA, durante o mês de Abril de 2016, em um Colégio Estadual na cidade de Amargosa, no interior da Bahia, no qual desenvolvemos o projeto de pesquisa intitulado "O uso do software Modellus no ensino de Física para Jovens e Adultos" do curso de mestrado em Ensino de Ciências e Matemática da UESB. Neste trabalho, procuramos construir subsunçores através de atividades realizadas com os Programas Word e Excel com os alunos da EJA, com o objetivo de facilitar a utilização do software Modellus no processo de ensino-aprendizagem de conceitos físicos, com base na Teoria da Aprendizagem Significativa de David Ausubel. Esta pesquisa tem caráter qualitativo, na qual aplicamos um questionário para fazer um levantamento dos conhecimentos prévios dos alunos sobre o uso do computador. Constatamos por meio de questionário que, dos dez estudantes que participavam do projeto, quatro dos alunos disseram que nunca tiveram contato com o computador. A partir desses resultados, modificamos a sequência didática anteriormente construída para possibilitar aos participantes um primeiro contato com a máquina e, consequentemente, inseri-los nessa proposta de ensino. Diante deste cenário, elaboramos uma unidade didática a respeito do uso do computador, utilizando os programas Word e Excel, visando estabelecer subsunçores para utilizar o software Modellus. Por outro lado, o estudo demonstra que os alunos que, inicialmente, disseram que já tinham contato com o computador mostraram dificuldades durante a sequência didática.

Palavras-chave: Tecnologia de Informação e Comunicação (TIC); Software; Física. 


\section{Use the Word and Excel for students to create EJA subsumers for software use Modellus}

Daniel de Jesus Melo Santos

Sergio Luiz Bragatto Boss

\section{Abstract}

This paper presents the research results developed with a group of high school in the Youth and Adult Education mode - YAE during the month of April 2016, in a State School in the town of Amargosa, in Bahia, in which we are developing the research project entitled "the use of Modellus software in teaching Physics for Young People and Adults" of the master's degree in Science education and Mathematics UESB. In this work, we seek to build subsumers through activities with the Word and Excel programs with students of YAE, in order to facilitate the use of Modellus software in teaching and learning physical concepts process, based on Meaningful Learning Theory David Ausubel. This research is qualitative, in which we applied a questionnaire to survey the students' prior knowledge about computer use. We found through a questionnaire that ten students participating the project, four students said they never had contact with the computer. From these results, we modify the didactic sequence previously constructed to allow participants a first contact with the machine and enter them in this teaching proposal. In this scenario, we developed a teaching unit about computer use, using the Word and Excel programs, to establish subsumers to the Modellus software use. On the other hand, the study shows that students who initially said they had contact with the computer showed difficulties during the teaching sequence.

Keywords: Information and Communication Technology (ICT); software; Physical. 


\section{Introdução}

O uso de computador no ensino de física se mostra como uma ferramenta de auxílio para novas estratégias de aprendizagem. "A necessidade de diversificar métodos para combater o insucesso escolar, que é particularmente nítido nas ciências exactas, conduziu ao uso crescente e diversificado do computador no ensino da Física”. (FIOLHAIS, 2003, p. 259). Diante deste cenário, nosso trabalho de pesquisa tem como objetivo geral ensinar conceitos de cinemática utilizando o software Modellus como recurso didático para criar um ambiente de aprendizagem com o uso do computador, para alunos de EJA.

Para dar início a nossa pesquisa, uma vez já selecionada a turma com a qual trabalharíamos, após a divulgação nas três turmas de EJA do noturno, apareceram dez alunos para participar do projeto, onde aplicamos um questionário inicial para avaliar alguns conhecimentos prévios mais gerais sobre a temática que seria trabalhada. Dentre estes conhecimentos, questionamos os alunos sobre qual a familiaridade que tinham com o computador e com o uso de qualquer software. Para a nossa surpresa, quatro estudantes responderam que não tinha familiaridade com o computador. Na medida em que "saber utilizar minimamente um computador” era um conhecimento prévio relevante e necessário para a nossa intervenção com o uso do Modellus, este questionário inicial foi de fundamental importância em nossa pesquisa. Pois, nos deu um maior entendimento sobre nossos alunos e, assim, nos possibilitou reestruturar o início da sequência didática que seria aplicada, dando maior atenção para o ensino do uso do computador e alguns softwares mais básicos. Não nos resta dúvida de que com esta reestruturação passamos a dar aos nossos aprendizes mais condições de apreender o conteúdo que seria ensinado e, por isso, julgamos relevante a socialização dos resultados do nosso primeiro questionário. O nosso objetivo com isto é marcar a fundamental necessidade de se considerar como conhecimentos prévios relevantes necessários para o aprendizado de conceitos científicos outros conhecimentos que não são necessariamente científicos, muitas vezes relacionados ao uso dos recursos didáticos.

Àqueles conhecimentos prévios relevantes necessários a Teoria da Aprendizagem Significativa de David Ausubel o qual denomina de subsunçores. Sendo assim, à luz deste referencial teórico, podemos dizer que o nosso trabalho inicial buscou identificar se nossos alunos tinham os subsunçores necessários para o processo de ensino-aprendizagem. Diante da negativa quanto aos conhecimentos básicos de informática, buscamos proporcionar aos alunos atividades que possibilitassem a construção dos subsunçores necessários para a utilização do software Modellus. Pois, este seria utilizado como recurso didático no processo de ensinoaprendizagem que tínhamos planejado. Cabe pontuar, brevemente, que a utilização do software enquanto recurso educacional está diretamente relacionado à capacidade de percepção do professor em relacionar a tecnologia a sua proposta educacional (TAJRA, 2007, 
p.74). Por meio de um software podemos ensinar; aprender ou, simplesmente, produzir trabalhos com excelentes apresentações. E foi buscando promover um processo de ensinoaprendizagem profícuo, que não se resuma apenas a produzir belas apresentações, é que nos debruçamos sobre esta pesquisa.

\section{Referencial Teórico}

\section{A Educação de Jovens Adultos - EJA}

A educação de Jovens e Adultos, destinada àqueles que não tiveram acesso ao Ensino Fundamental e Médio na idade própria, é constituída por alunos moradores de localidades populares; operários e operárias assalariados da construção civil e também trabalhadores de atividades informais, vinculados ao comércio e ao setor doméstico. Deveremos compreender a EJA, enquanto processo de formação humana plena, que, embora instalado no contexto escolar, deverá levar em conta as formas de vida, trabalho e sobrevivência dos jovens e adultos que se colocam como principais destinatários dessa modalidade de educação. De acordo com o Artigo 37 da LDB: a "Educação de Jovens e Adultos será destinada àqueles que não tiveram acesso ou continuidade de estudos no Ensino Fundamental e Médio na idade própria”. A lei ainda diz, no Artigo 38, que os "sistemas de ensino assegurarão gratuitamente aos jovens e adultos, oportunidades educacionais apropriadas”. Antes disso, porém, a Constituição de 1988, no Artigo 208, já dizia que era dever do Estado garantir "O Ensino Fundamental, obrigatório e gratuito, inclusive para aqueles que não tiveram acesso na idade própria”. Consequentemente, a EJA orienta-se pelos ideários da Educação Popular: formação técnica, política e social. Para Freire (2001, p. 15), o conceito de Educação de Adultos vai se movendo na direção da Educação Popular, na medida em que a realidade vai fazendo exigências à sensibilidade e à competência científica dos educadores e educadoras.

\section{A Educação de Jovens e Adultos no Estado da Bahia}

A modalidade do Ensino de Jovens e Adultos no Estado da Bahia vem sendo oferecida no sistema público estadual de ensino desde o início da década de 90, mantendo-se de acordo com o preceito da Constituição Federal de 1988 e da Lei de Diretrizes e Bases da Educação de 1996.

O Programa da Educação Básica de Jovens e Adultos instituída no ano de 1992, para atendimento a pessoas sem escolarização, ocorrendo na rede de ensino com a formulação proposta pela Gerência de Educação Básica de Jovens e Adultos, com o apoio de consultores, de um projeto de curso denominado Aceleração I e II ${ }^{9}$ visando à oferta do ensino fundamental, ${ }^{9}$ Autorizados pela Resolução CEE n. ${ }^{\circ}$ 032/92 - D.O. 27/08/92, Portaria n. ${ }^{\circ}$ 066/98 - D.O. 08/01/98.
ISSN 2526-2882 
nos termos preconizados pela LDB n. ${ }^{\circ}$ 9394/96, ou seja, adequado às características dos estudantes, às suas condições de vida e trabalho, levando em conta seus saberes e experiências. A Aceleração I corresponde, aproximadamente, ao primeiro segmento do ensino fundamental (e se apresenta dividida em dois estágios de um ano cada), e a Aceleração II (também dividida em dois estágios de um ano cada) ao segundo segmento.

O programa de Aceleração I será preferencialmente oferecido, aos iniciados em processos de leitura e escrita, tanto oriundos de projetos de alfabetização promovidos pela própria Secretaria, que serão conduzidos para a continuidade no programa institucionalizado, quanto oriundos de outras ações promovidas por ONGs, sindicatos, fundações, que a rede pública busca acompanhar e assumir a continuidade, como, ainda, atende pessoas com passagens anteriores pela escola (ou por outros modos de aprender).

Trabalhando com a premissa de que os conhecimentos de mundo e os saberes da prática permitem aos jovens e adultos avançar em seus processos de aprendizagem, sustentouse a ideia da aceleração como princípio da educação, oferecendo um curso com duração total de quatro anos. Além disso, essa foi uma das muitas estratégias que os poderes públicos encontraram para vencer as restrições impostas pelo FUNDEF à EJA, concorrendo, assim, a recursos de programas federais (Programa Aceleração da Aprendizagem) e aplicando-os, nessa área.

No período de execução, em que o Programa aconteceu, observou-se um crescimento de matrículas o que representa, como política pública, uma expansão do atendimento - dever do poder público - sem, no entanto, universalizar o acesso para todos os educandos. Do ponto de vista de resultados, ou seja, dos concluintes do Programa, os dados revelam timidamente um pequeno crescimento, ao final da etapa de Aceleração II.

A Partir desses resultados e, pela necessidade de diminuir os índices de analfabetismo e também de oportunizar a esses jovens e adultos a continuidade de seus estudos, foi preciso reinserir os Programas de Aceleração I e II no marco legal que hoje suporta a educação de jovens e adultos.

Em 2009, a Secretaria Estadual de Educação da Bahia começou a trabalhar com uma nova proposta de Educação de Jovens e Adultos, o Tempo Formativo. Esse modelo tem por objetivo tornar o aprendizado do aluno, o mais próximo possível da sua realidade e, assim, diminuir as taxas de evasão escolar nessa modalidade de ensino, que de acordo com os dados da Pesquisa Nacional por Amostra de Domicilio (PNAD/IBGE) foi superior a 42\%. Nesse sentido, o Tempo Formativo foi pensado para se adequar as necessidades reais do público a qual se destina.

A abrangência da EJA no Estado da Bahia é compreendida como uma modalidade apropriada ao jovem e adulto trabalhador ao qual indica que esta atenda a jovens e adultos que ISSN 2526-2882 
tenha idade a partir dos 18 anos. Segundo a Proposta "Educação de Jovens e Adultos: Aprendizagem ao Longo da Vida (2009)”, a qual se torna a Política de Educação de Jovens e Adultos do Estado da Bahia, sendo elaborada pela Secretaria de Educação do Estado da Bahia no qual, foram ouvidos os principais sujeitos da EJA: educandos (as), educadores, gestores e coordenadores pedagógicos das Diretorias Regionais de Educação - DIREC, bem como representantes dos diversos segmentos que dão forma ao Fórum Estadual de EJA, quais sejam: Universidades (Universidade do Estado da Bahia - UNEB e Universidade Federal da Bahia UFBA), Movimentos Sociais (Movimento de Educação de Base - MOVA), Sistema S (Serviço Social da Indústria - SESI), Organização Não-governamental (Centro de Estudos e Assessoria Pedagógica - CEAP), Gestão Pública (Secretaria de Educação do Estado - SEC/BA e Secretaria Municipal de Educação e Cultura - SMEC/SSA) Fóruns Regionais de EJA. A intenção da Proposta é legitimar a EJA como modalidade de Ensino e principalmente que essa proposta expresse as reais demandas e as expectativas dos ideários populares, principais destinatários desta modalidade de Educação. Para Haddad (2007, p. 8), "A EJA é uma conquista da sociedade brasileira”, pois durante o processo histórico da educação no Brasil, esta modalidade de ensino sempre esteve à margem das políticas públicas nacionais de educação, e sua oferta em forma de campanhas de massa, visava o atendimento de objetivos imediatistas de diminuição do índice de analfabetismo.

\section{Teoria da Aprendizagem Significativa: Criação de Subsunçores}

Neste trabalho, usamos como base a Teoria da Aprendizagem Significativa de David Ausubel. Ressaltamos que devido aos limites do presente texto, pontuaremos apenas aspectos essências desta teoria, necessários para analisar e discutir os dados apresentados aqui.

A Aprendizagem Significativa envolve a aquisição de novos significados e esses novos significados são produtos da Aprendizagem Significativa. Esta aprendizagem ocorre à medida que informações novas e potencialmente significativas ancoram-se, mais frequentemente, a ideias relevantes mais gerais e inclusivas na estrutura cognitiva do aprendiz (AUSUBEL, 2000, p. 93). Portanto, torna-se indispensável uma análise prévia daquilo que se vai ensinar, buscando a melhor maneira de relacionar, explicitamente, os aspectos mais importantes do conteúdo / matéria de ensino aos aspectos especificamente relevantes da estrutura cognitiva do aprendiz. Os conhecimentos relevantes da estrutura cognitiva, que servem de ancoradouro para a nova informação, são denominados por Ausubel de subsunçores. O subsunçor é uma estrutura específica à qual uma nova informação pode se integrar a estrutura cognitiva do aprendiz. Quando não existirem os subsunçores, deveremos construí-los, seja através de aula expositiva, um vídeo, uma música etc. Porém, caso o aprendiz não tenha os subsunçores, Ausubel "recomenda o uso de organizadores prévios que sirvam de ancora para a nova ISSN 2526-2882

$$
20
$$


aprendizagem e levem ao desenvolvimento de conceitos subsunçores” (AUSUBEL, 2000, p. $11)$.

Os organizadores prévios são materiais introdutórios que se apresentam no inicio da lição. Eles estabelecem uma ligação entre as ideias relevantes que o aluno já possui com a tarefa de aprendizagem que lhe vai ser proposta. Para que os organizadores prévios possam funcionar de forma eficaz para diversos alunos, Ausubel (2000, p.11), propõe que "apresentem-se os organizadores prévios a um nível mais elevado de abstracção, generalidade e inclusão do que os materiais a serem apreendidos". Esses organizadores possuem como objetivo, aumentar a pré-disposição para aprendizagem significativa; fornecer um suporte para a tarefa de aprendizagem; relacionar as novas ideias com as que o aluno já domina, permitindo assim que sejam mais bem discriminada e assimilada e, fazer uma ponte entre o que é sabido pelo aluno e que é preciso saber para aprender mais rapidamente o novo material. Os organizadores prévios baseiam-se na ideia de que o fator que mais influencia a aprendizagem é aquilo que o aluno já conhece, portanto, o planejamento de ensino deve ter como ponto de partida o levantamento das competências e conhecimentos já dominados pelo aluno.

- Materiais de ensino potencialmente significativos: durante a lição, estes materiais podem ser apresentados sob a forma de exposições, discussões, filmes, experiências, leituras, etc. A finalidade da sua utilização será manter a atenção do aluno e explicitar como é que os conteúdos estão organizados. O meio principal é a exposição do professor enquanto que os recursos da tecnologia ajudam a esclarecer conceitos e proposições relevantes, porém, são mais um complemento. Esses materiais de ensino têm a finalidade de manter a atenção do estudante e de explicitar como é que os conteúdos estão organizados para ajudar o aluno a perceber sua ordenação lógica e a estabelecer relações entre ideias. Para que ocorra a Aprendizagem Significativa é necessário que:

1 - O material a ser assimilado seja potencialmente significativo, ou seja, não arbitrário e não literal entre os conhecimentos prévios e os novos conhecimentos;

2 - Haja a existência de um conteúdo mínimo na estrutura cognitiva do aluno, com subsunçores suficientes para suprir as necessidades relacionais;

3 - O aprendiz apresente uma disposição para aprender e que não esteja apenas interessando em memorizar mecanicamente o novo conteúdo apresentado. (AUSUBEL, 2000, p. 6).

A aprendizagem significativa, não é sinônimo de aprendizagem de material significativo. Segundo Ausubel (2000):

Em primeiro lugar, o material de aprendizagem apenas é potencialmente significativo. Em segundo, deve existir um mecanismo de aprendizagem significativa. O material de aprendizagem pode consistir em componentes já 
significativas (tais como pares de adjetivos), mas cada uma das componentes da tarefa da aprendizagem, bem como esta como um todo (aprender uma lista de palavras ligadas arbitrariamente), não são "logicamente" significativas. Além disso, até mesmo o material logicamente significativo pode ser apreendido por memorização, caso o mecanismo de aprendizagem do aprendiz não seja significativo. (AUSUBEL, 2000, p. 1).

O aluno ao manifestar uma pré-disposição para aprender, um determinado conhecimento, ele deverá intencionalmente, relacionar, de forma não literal e não arbitrária, o novo material a ser aprendido, com alguma ideia, alguma informação ou algum conhecimento em sua estrutura cognitiva.

Para nortear a maneira e a sequência dos conceitos a serem trabalhados em sala de aula, Ausubel propõe dois processos: diferenciação progressiva e reconciliação integrativa. Diferenciação Progressiva: O conteúdo a ser apresentado aos alunos deve ser programado de maneira que os conceitos mais gerais da disciplina ou conteúdo sejam apresentados em primeiro lugar, e, pouco a pouco, introduzidos os conceitos mais específicos. Reconciliação Integrativa: A programação do material a ser apresentado ao aluno deve ser feita de maneira que haja exploração de relações entre ideais, apontando semelhança e diferenças entre conceitos relacionados. No trabalho pedagógico ela deve acontecer em dois contextos: na preparação do material instrucional, e no relacionamento das ideias nele contidas com a estrutura cognitiva do aluno. (MOREIRA; MASINI, 1982, p. 21-2).

Na Teoria da Aprendizagem Significativa, AUSUBEL (2000, p. 93), propõe três formas de aprendizagem por assimilação: Subordinada, Superordenada e Combinatória.

\section{Aprendizagem Subordinada}

Segundo Ausubel, a maior incidência de aprendizagem significativa é do tipo subordinada, ou seja, a nova ideia aprendida se encontra hierarquicamente subordinada às ideias preexistentes. Os significados para os materiais de aprendizagem apresentam uma relação de subordinação à estrutura cognitiva. Coll, Marchesi e Palácios (2007, p. 116) comentam que a estrutura cognitiva do sujeito responde a uma organização hierárquica na qual os conceitos se conectam entre si mediante relações de subordinação, ou seja, parte dos conceitos mais gerais para os mais específicos.

\section{Aprendizagem superordenada}

Este tipo de aprendizagem é bem menos comum do que a subordinada. Nesta forma de aprendizagem o novo conceito é mais geral e inclusivo que os conceitos subsunçores. Ocorre quando um conceito ou proposição mais geral do que algumas ideias já estabelecidas na estrutura cognitiva do estudante, é adquirido e passa a ser assimilado. O novo material a ser 
aprendido apresenta uma relação de superordenação com a estrutura cognitiva, no momento em que o indivíduo aprende um conceito ou proposição mais abrangente. Para Ausubel, Novak e Hanesian (1980, p. 48-57) a nova aprendizagem será superordenada quando se aprende uma nova proposição inclusiva que condicionará o surgimento de várias ideias, ocorrendo no curso do raciocínio ou quando o material apresentando é organizado indutivamente ou envolve a síntese de ideias compostas.

\section{Aprendizagem Combinatória}

A aprendizagem de novas proposições que não apresentam relação subordinada nem superordenada com ideias relevantes já adquiridas anteriormente na estrutura cognitiva do estudante é denominada aprendizagem combinatória. Conforme POZO (1998, p. 38) na aprendizagem significativa combinatória, a ideia nova e as ideias já estabelecidas não estão relacionadas hierarquicamente, porém se encontram no mesmo nível, não sendo nem mais específica nem mais inclusiva do que outras ideias.

Um dos princípios programáticos da teoria da Aprendizagem Significativa, diz respeito a Consolidação, que juntamente com a diferenciação progressiva, a reconciliação integrativa e a organização sequencial deverão insistir no domínio do que está sendo estudado, antes que novos materiais sejam introduzidos, buscando assegurar contínua prontidão na matéria de ensino e sucesso na aprendizagem sequencialmente organizada. Segundo Ausubel:

Nunca se deve introduzir novo material na sequência até se dominarem bem todos os passos anteriores. Este princípio também se aplica aos tipos de aprendizagem intratarefas, nos quais cada tarefa componente (bem como conjuntos integrais de matérias). A consolidação, como é obvio, alcança-se através da confirmação, correcção e clarificação, no decurso do retorno (feedback), e através da prática diferencial e da revisão, no decurso da exposição repetida, com retorno, ao material de aprendizagem. (AUSUBEL, 2000, p. 172).

Contudo, o princípio da Consolidação deve ser compatibilizado com a progressividade da aprendizagem significativa e com a diferenciação progressiva e a reconciliação integrativa.

\section{Metodologia da Pesquisa}

A metodologia segue os parâmetros da abordagem qualitativa. Esta pressupõe o contato direto e prolongado do pesquisador com o ambiente e a situação que está sendo investigada para a obtenção de dados descritivos. Dá ênfase muito mais no processo e na retratação da perspectiva dos participantes (LUDKE, 1986; BOGDAN; BIKLEN, 1994). A técnica de pesquisa foi a observação participante. Para coleta de dados, neste primeiro momento, foi elaborado um questionário, cujo objetivo era levantar os conhecimentos prévios dos alunos a respeito do uso 
do computador. Os indivíduos da pesquisa são alunos de um Colégio Estadual da cidade de Amargosa/BA, da zona urbana e rural, na modalidade EJA do EIXO-7, da turma C, que estudam no noturno e que foram convidados a participar dessa pesquisa.

\section{A Descrição das Atividades}

Devido aos limites de páginas do trabalho, apresentaremos a discussão de parte dos dados colhidos para a pesquisa. Foi aplicado no primeiro dia de aula um questionário com o objetivo de levantar os conhecimentos prévios e os subsunçores dos alunos sobre o uso do computador. Numa primeira análise das respostas ao questionário, notamos que havia quatro alunos que nunca tiveram contato com a tecnologia. Após a tabulação e análise dos dados decidimos mudar o rumo da pesquisa e iniciar uma sequência didática com ênfase no uso do computador. Isto porque a nossa proposta previa o uso do software Modellus para trabalhar com os conceitos de Física. Pois, segundo a Teoria da Aprendizagem Significativa de David Ausubel a aprendizagem se apoia a partir do conhecimento prévio do aluno. Vale salientar, que por motivo dos limites de espaço deste artigo, apresentaremos apenas uma breve introdução das primeiras aulas que ocorreram no mês de abril de 2016. Posteriormente, apresentaremos um quadro completo que representa a sequência didática com base na teoria da Aprendizagem Significativa.

De início, optamos por trabalhar com os programas Word e Excel. Inicialmente, utilizamos um texto sobre a vida do educador Paulo Freire (o objetivo era mostrar em um breve texto a biografia deste educador e sua importância para a educação de jovens e adultos). Foi solicitado que cada aluno fizesse a leitura de um parágrafo para socializar as informações. Após a leitura, solicitamos aos alunos que abrissem o programa Word e digitassem o texto, copiando ipsis litteris. Neste momento um dos pesquisadores ficou andando pela sala de aula e auxiliando os alunos que ainda não tinham contato com o computador. No início, os discentes se sentiram acanhados. Então, deixamos que se organizassem da forma que fosse mais interessante e confortável para eles. Ficaram em duas duplas utilizando o mesmo computador, portanto quatro alunos, justamente os alunos que nunca tinham tido contato com a máquina. Desta forma, pudemos dar um maior suporte e fazer algumas intervenções a partir das suas dúvidas. Também buscamos observar como os outros alunos estavam trabalhando com a digitação do texto. A partir disso, visualizamos que os alunos que responderam ao questionário dizendo já terem contato com o computador, não tinham tanta familiaridade quanto imaginavam ter. Analisando as indagações desses estudantes, conforme segue abaixo:

Aluno C2: "Professor já usei o computador, porém faz muito tempo que não mexo na máquina, daria para o senhor dizer como faço para passar para a outra linha?”. 
Aluno C8: "Professor como faço para colocar o acento na palavra geracoes (grifo do autor)".

Aluno C10: "Professor não consegui ligar o computador, o que devo fazer?"

Pensamos estar no caminho certo, na trilha da possível construção de subsunçores pelos alunos. Primeiro conhecendo o computador para depois utilizarem o software Modellus no ensino de conceitos físicos.

\section{Os dados da pesquisa}

Devido aos limites de páginas do trabalho, os dados coletados não serão apresentados em sua totalidade. No início da nossa pesquisa coletamos dados por meio de um questionário sobre os conhecimentos prévios dos alunos em relação ao uso do computador e sobre os conceitos básicos de Cinemática. Nesta aula estavam presentes dez alunos que responderam ao questionário de pesquisa. Após tabulação e análise dos dados, constatamos que quatro alunos que participavam do grupo de pesquisa nunca tiveram qualquer contato com o computador. Outro dado relevante é que esses estudantes são oriundos da zona rural da cidade de Amargosa/BA. Então, decidimos mudar a sequência didática e fazermos uma introdução sobre como utilizar o computador. Pois, se não fosse desta forma não seríamos fiéis ao nosso referencial teórico, uma vez que os discentes não tinham os subsunçores iniciais para utilizar o software Modellus. Logo, não poderíamos continuar com a proposta de utilizar um software sem que os alunos não soubessem utilizar o computador. No Gráfico1, apresentamos os dados parciais da pesquisa.

Gráfico 1

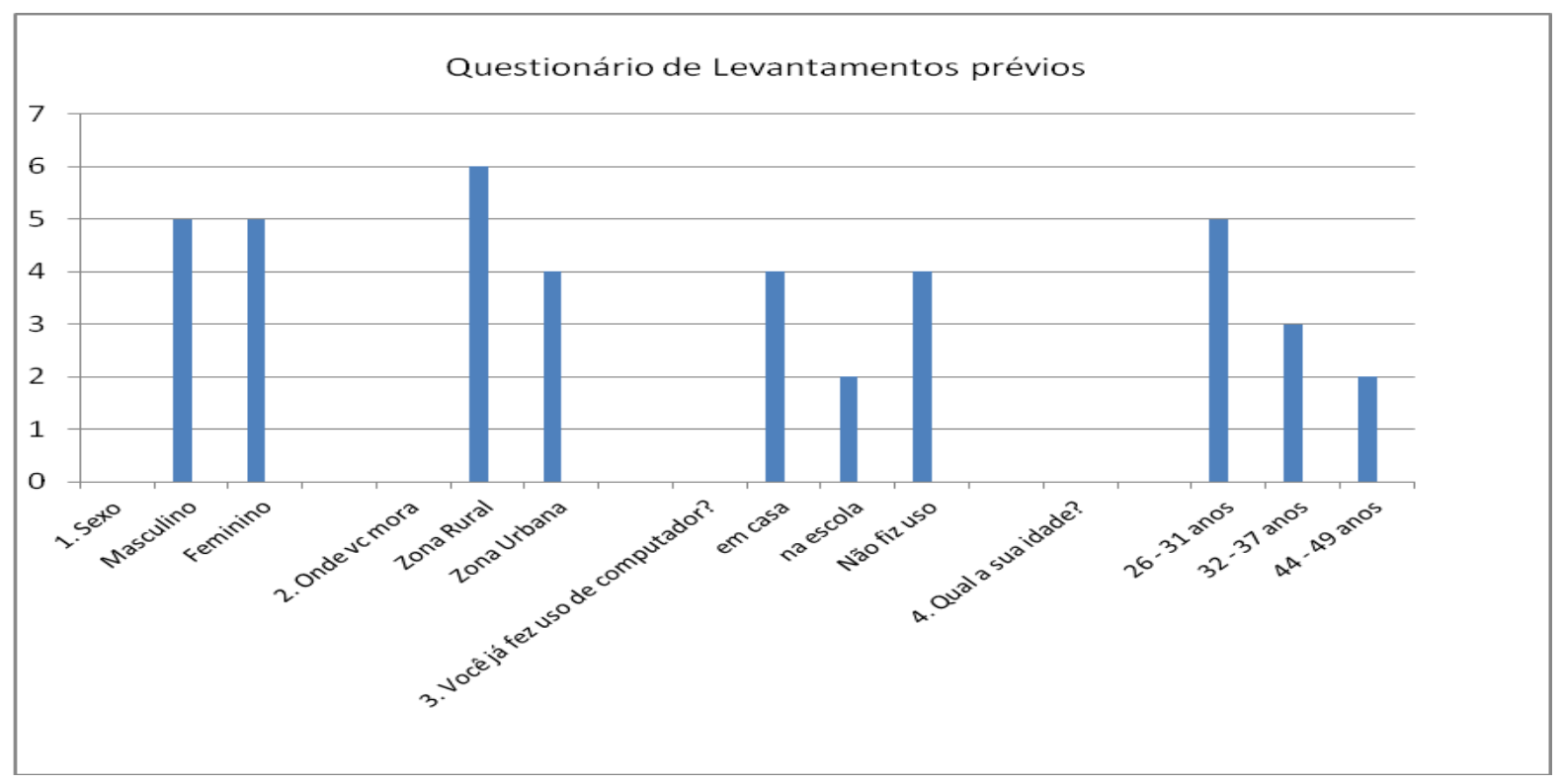

Fonte: Os autores 
Podemos observar no gráfico que os alunos que participam deste projeto têm idade acima de 25 anos e, a maioria mora na zona rural da cidade, o grupo é formado em quantidade igual entre homens e mulheres. Porém, apenas duas pessoas utilizaram o computador na escola, sendo necessário um estudo mais aprofundado para analisar o motivo pelo qual numa amostra de dez alunos apenas dois utilizaram o computador na escola. Diante dessa constatação construímos uma sequência didática na perspectiva da Teoria da Aprendizagem Significativa de David Ausubel, conforme o quadro1.

Quadro 1 - Conhecendo e trabalhando com o computador: Programas Word e Excel

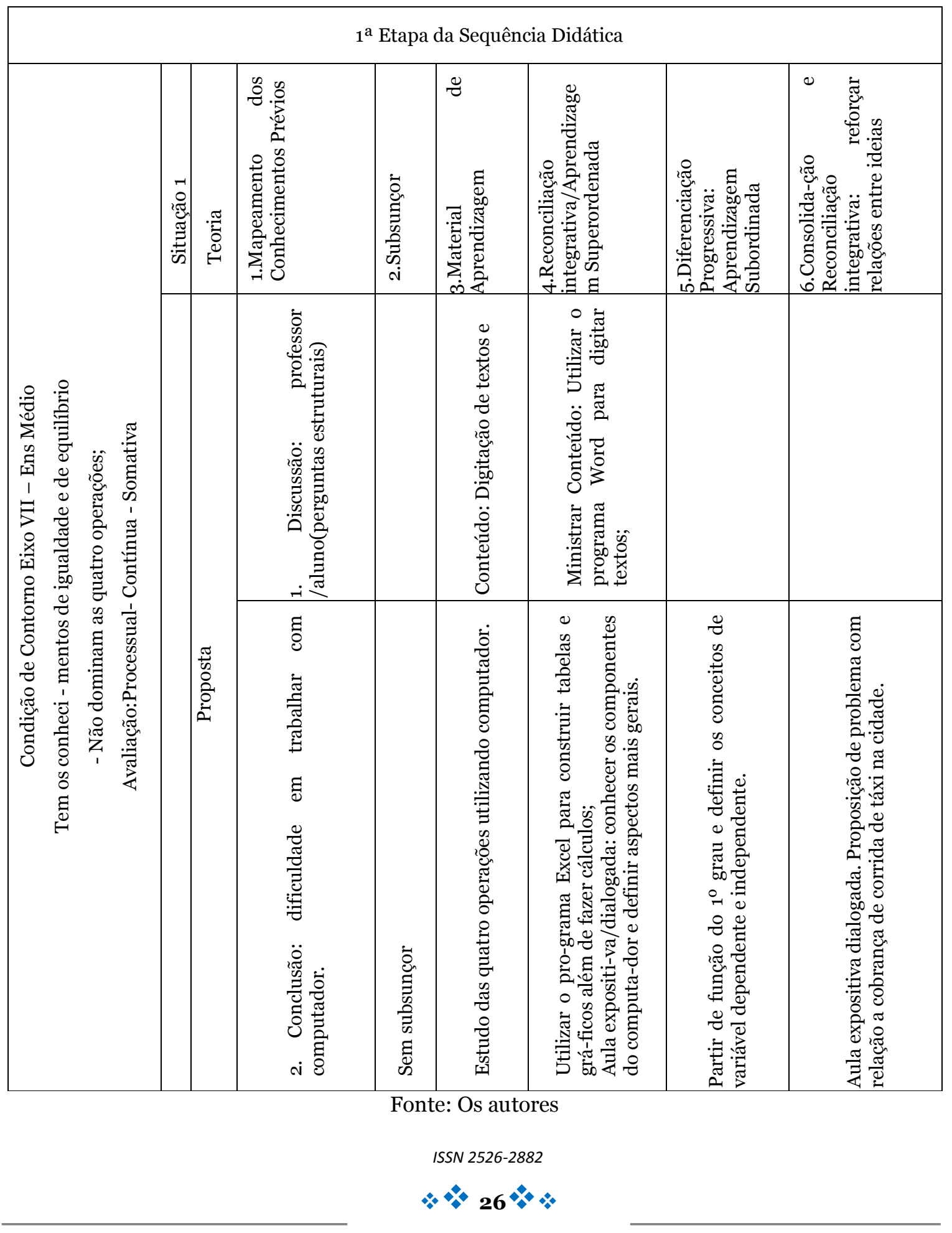




\section{Resultados e discussões}

Apontaremos, nesta seção, apenas algumas considerações sobre os resultados encontrados, pelo motivo de que se trata de uma primeira análise. No início da sequência didática, solicitamos aos alunos que cada um fizesse a leitura de um parágrafo do texto sobre a vida do educador Paulo Freire. Buscávamos, assim, socializar as informações e abrir um momento de discussão sobre o que eles entenderam em relação ao texto apresentado. A discussão do texto sobre a biografia de Paulo Freire foi uma estratégia montada para situar os alunos como grupo e, também, possibilitar aos estudantes a interpretação do texto e que este "fizesse sentido" para eles. Entendemos que seja importante a leitura para que os alunos possam refletir sobre o que estejam digitando e pudessem entender a importância de ler e escrever textos sobre vários temas seja na escola, ou em outro ambiente.

Após a leitura e discussões sobre a importância desse educador para EJA, solicitamos que os alunos abrissem o programa Word e digitassem o texto. Neste momento, constatamos pelas indagações dos alunos que eles tinham muitas dúvidas a respeito, por exemplo, de como colocar acentuação numa palavra e de como mudar o tipo de letra, dentre outras. Essas dúvidas foram imediatamente socializadas para o grupo com a intenção de melhorar a interação dos alunos com a máquina, porém os estudantes levaram quatro aulas para digitar o texto de uma página, ainda assim, houve relatos de que estavam gostando da atividade de digitação porque era uma maneira de possibilitar uma maior interação com as funções da máquina. Após a digitação do texto solicitamos que esses alunos comentassem sobre suas impressões sobre a atividade proposta, onde eles não foram muito específicos em relação a atividade, porém, houve unanimidade sobre a experiência de realizar uma atividade com o computador na escola para melhorar os seus conhecimentos a respeito do computador, haja vista, que segundo esses estudantes ainda não haviam realizado atividades no laboratório de informática da escola.

No dia seguinte preparamos uma aula expositiva com apresentação em PowerPoint sobre as principais funções do Excel, após a aula, abrimos discussão para o grupo, onde surgiram algumas dúvidas. Essas dúvidas foram imediatamente socializadas para o grupo com a intenção de melhorar a interação dos alunos com a máquina que, segundo a Teoria da Aprendizagem Significativa, possibilita fazer a reconciliação integrativa e a diferenciação progressiva. Pois, para Ausubel:

O processo de assimilação sequencial de novos significados, a partir de sucessivas exposições a novos materiais potencialmente significativos, resulta na diferenciação progressiva de conceitos ou proposições, no consequente aperfeiçoamento dos significados e numa potencialidade melhorada para se fornecer ancoragem a aprendizagens significativas posteriores. (AUSUBEL, 2000, p. 106). 
Acreditamos que os conceitos de reconciliação integrativa e da diferenciação progressiva durante a aplicação da sequência didática foram importantes para que os alunos pudessem obter os subsunçores necessários para a utilização do software Modellus.

\section{Considerações Finais}

A metodologia utilizada para conhecer e trabalhar com o computador proporcionou a possibilidade de construção dos subsunçores necessários para se utilizar o software Modellus. Além disso, acreditamos que com essa iniciativa possibilitamos uma inserção dos alunos da EJA para o uso da tecnologia. Pode-se verificar que este tipo de trabalho poderá contribuir para a aprendizagem significativa por meio da construção dos subsunçores, adquirindo novos conhecimentos e expandindo os já existentes. Consideramos que os diversos modos de utilização do computador no ensino poderão levar os alunos a obter aquisição de dados; simulação e, realidade virtual, o que pode permitir a diversificação de novas possibilidades para ensinar os conceitos de física. Portanto, o professor dispõe de novas condições para ampliar a sua forma de ensinar e, consequentemente, possibilitar aos estudantes uma variedade de meios para aprender o conteúdo a ser ensinado.

Ao levantar os conhecimentos prévios dos alunos sobre o assunto abordado, criaramse possibilidades, para facilitar a compreensão da situação que seria proposta posteriormente. Isso se mostrou profícuo na medida em que estes conhecimentos foram utilizados, mais tarde, durante a execução da sequência didática.

De modo geral, o trabalho nos permitiu concluir sobre a importância da utilização dos recursos tecnológicos para melhorar a aprendizagem dos alunos sobre conceitos físicos, principalmente dos estudantes da EJA. Acreditamos que com essa pesquisa, possamos utilizar desses resultados para trabalhos futuros e, consequentemente, ampliar estudos sobre o uso do software no ensino de Física, ou mesmo, que essa pesquisa possa servir de referência para outros pesquisadores, uma vez que, a atividade aplicada permitiu obter resultados positivos na aprendizagem de Física.

\section{Referências}

AUsubel, D. P. Aquisição e Retenção de Conhecimentos: Uma Perspectiva Cognitiva. Lisboa: Paralelo, 2000.

AUSUBEL, D. P.; NOVAK, J. D.; HANESIAN, H. Psicologia Educacional. Rio de Janeiro: Interamericana, 1980.

BOGDAN, R.; BIKLEN, S. Investigação qualitativa em educação: uma introdução à teoria e aos métodos. Porto, Porto Editora, 1994. p. 47- 51. 
BRASIL. Lei n. 9.394/96: Lei de Diretrizes e Bases da Educação Nacional (LDB). Brasília. $\quad$ MEC, $1996 . \quad$ Disponível <http://portal.mec.gov.br/arquivos/pdf/ldb.pdf>. Acesso em: 10 abril 2016.

COLL, C.; MARCHESI, A.; PALACIOS, J. Desenvolvimento psicológico e educação: psicologia da educação escolar. $2^{\mathrm{a}}$ ed. Porto Alegre: Artmed, 2007.

CONSTITUIÇÃO FEDERAL DO BRASIL.

FIOLHAIS, C.; TRINDADE, J. Física no Computador: o Computador como uma Ferramenta no Ensino e na Aprendizagem das Ciências Físicas. Revista Brasileira de Ensino de Física, v. 25, n.3, p. 259-272, 2003.

FREIRE, Paulo. Educação de adultos: Algumas reflexões. In: GADOTTI, Moacir; ROMÃO, José (Org.). Educação de Jovens e Adultos: Teoria, prática e proposta. Vol. 5. São Paulo: Cortês: Instituto Paulo Freire, 2001.

HADDAD, Sérgio. et al. Novos Caminhos em Educação de Jovens e Adultos - EJA: Um estudo de ações do poder público em cidades de regiões metropolitanas brasileiras. Editora Global, São Paulo, 2007.

LÜDKE, Menga. André, M. E. D. A. Pesquisa em Educação: abordagens qualitativas. São Paulo: EPU, 1986.

MOREIRA, M. A.; MASINI, E. F. S. Aprendizagem Significativa - a teoria de David Ausubel. São Paulo, Moraes, 1982.

POZO, J. I. Teorias cognitivas da aprendizagem. $3^{\text {a }}$. ed. São Paulo: Artes Medicas, 1998. TAJRA, Sanmya Feitosa. Informática na educação. $7^{\mathrm{a}}$. ed. São Paulo: Érica, 2007.

SANTOS, D. J. M.; BOSS, Sergio Luiz Bragatto. O Uso do Computador para Criar Subsunçores na Utilização de Software no Ensino de Física. In: V Encontro Internacional de Alfabetização e Educação de Jovens e Adultos (ALFAeEJA) - Préabertura Salvador/BA, 2018. Anais DO V ALFAeEJA - Encontro de Préabertura de Salvador, p. 119-127, 2018.

\section{Biografia Resumida}

Daniel de Jesus Melo Dos Santos: Licenciado em Física pela Universidade Federal da Bahia - UFBA/Campus Salvador; Bacharelado em Ciências Estatísticas pela Escola Superior de Estatística da Bahia - ESEB; Especialista em Física pela Faculdade Gabriel da Palha - FASG/Campus Santo Antonio; Especialista em Matemática pela Universidade Estadual da ISSN 2526-2882 
Bahia - UNEB/Campus Alagoinhas; Mestre em Educação em Ciências e Matemática pela Universidade Estadual do Sudoeste da Bahia - UESB/Campus Jequié; Professor de Física do Colégio Estadual Pedro Calmon/Amargosa/Bahia; Professor de Estatística da Faculdade Maria Milza -

FAMAM/Mangabeira/Bahia; Técnico em Física da Universidade Federal do Recôncavo da Bahia - UFRB/Amargosa/Bahia; Integrante do Grupo de Estudo e Pesquisa em Física e Ensino de Ciências - PANACUM/ Universidade Federal do Recôncavo da Bahia/UFRB

e-mail: danielmelo84@hotmail.com

Sergio Luiz Bragatto Boss: Licenciado em Física pela Universidade Estadual Paulista - UNESP/Bauru/São Paulo; Mestre e Doutor em Educação para a Ciência pela Universidade Estadual Paulista - UNESP/Bauru/São Paulo; Professor Adjunto da Universidade Federal do Recôncavo da Bahia - UFRB/Amargosa/Bahia; Coordenador do Grupo de Estudo e Pesquisa em Física e Ensino de Ciências - PANACUM/ Universidade Federal do Recôncavo da Bahia/UFRB.

e-mail: serginhoboss@gmail.com 